\title{
Impact of Cognitive Impairment on Adherence to Treatment and Self-Care in Patients with Type 2 Diabetes Mellitus
}

This article was published in the following Dove Press journal: Diabetes, Metabolic Syndrome and Obesity: Targets and Therapy

\author{
Natalia Świątoniowska- \\ Lonc (1D) \\ Jacek Polański \\ Wojciech Tański \\ Beata Jankowska-Polańska' \\ 'Department of Clinical Nursing, Faculty \\ of Health Science, Wroclaw Medical \\ University, Wroclaw, Poland; \\ ${ }^{2}$ Department of Internal Diseases, \\ Occupational Medicine, Hypertension \\ and Clinical Oncology, Wroclaw Medical \\ University, Wroclaw, Poland; \\ ${ }^{3}$ Department of Internal Medicine, 4th \\ Military Teaching Hospital, Wroclaw, \\ Poland
}

Background: Elderly patients with diabetes have a significantly increased prevalence of mild cognitive impairment compared with people of similar age without diabetes. Tasks related to diabetes self-management involve multiple cognitive skills and processes, such as memory, attention, planning, and calculating. Impaired cognitive function can threaten the patient's ability to perform self-monitoring. The objectives of the study were: to assess cognitive deficits and the level of self-care in elderly patients with diabetes, to identify correlations between cognitive deficits and self-care, and to determine which variables influence self-care behaviors and cognitive deficits.

Methods: The study involved 169 patients with type 2 DM. Standardized tools were used: Mini-mental State Examination (MMSE) to assess cognitive function and the Self-Care of Diabetes Inventory (SCODI) to assess the level of self-care. Socioclinical data were taken from the hospital records.

Results: $56.8 \%$ of patients had cognitive impairment (MMSE $\leq 26$ ). In the comparative analysis, patients with cognitive impairment had significantly lower results in all domains of the SCODI: self-care maintenance (72.9 vs 75), self-care monitoring (53.1 vs 56.3), selfcare management (71.9 vs 84.4 ), self-care confidence (79.5 vs 86.4). Correlation analysis showed that the MMSE score correlates significantly and positively $(p<0.05 ; r>0)$ with all SCODI subscales, and the higher the MMSE score the higher the level of self-care (A: $r=0.252, B: r=0.244, C: r=0.019, D: r=0.28$ ).

Conclusion: In this elderly type 2 diabetes population, and using only one test to verify the cognitive function, self-care management was worse in terms of self-care management (blood glucose control). Cognitive function components are independent determinants of self-care in patients with type 2 diabetes. Recall is an independent predictor of self-care maintenance, and writing a predictor of self-care monitoring.

Keywords: adherence, diabetes, cognitive impairment, self-care

\section{Introduction}

Around 422 million people globally, and 60 million in Europe, have diabetes. Type 2 diabetes accounts for $90 \%$ of these cases and is considered a leading lifestyle disease. ${ }^{1}$ In 2010 , the incidence of diabetes per 1000 people aged 65-79 years was $12.4 .^{2}$ In 2018, there were 2.9 million adults (including 1.3 million adult men) with diabetes mellitus in Poland, which corresponds to $9.1 \%$ of the adult population. Among adults, the most numerous group of diabetics in 2018 was that of women aged between 65 and 74 years (over 0.5 million). ${ }^{3}$ Although the burden of diabetes
Correspondence: Beata JankowskaPolańska

Department of Clinical Nursing, Faculty of Health Science, Wroclaw Medical University, K. Bartla 5, Wroclaw 5I-6I6, Poland Tel +48 717841824

Fax +48 7I 3459324

Email beata.jankowska-polanska@umed. wroc.pl
Diabetes, Metabolic Syndrome and Obesity: Targets and Therapy 2021:14 193-203

DovePress f in 口 
is often described in terms of its impact on working-age adults, diabetes in older adults is linked to higher mortality, impaired functional status, and increased risk of institutionalization. ${ }^{4}$ Diabetes management is based on pharmaceutical treatment, education, and self-care. ${ }^{5}$ Strict metabolic control and self-care ability can improve diabetes treatment outcomes and considerably reduce the risk of complications. Self-management refers to the individual's ability to manage the symptoms, treatment, physical and psychosocial consequences, and lifestyle changes inherent to living with a chronic condition. ${ }^{6}$ Although the benefits of diabetes self-care are well known, few elderly patients practice self-care in diabetes. Only a small proportion of patients achieve normal glycated hemoglobin levels. ${ }^{7}$ Available publications indicate that the level of self-care in polish patients with diabetes ranges between $30 \%$ and $50 \%{ }^{5,8,9}$ The rates of adherence to blood glucose self-monitoring are similar. As few as $65.1 \%$ of patients comply with the relevant guidelines, and fewer than half fully adhere to blood glucose self-monitoring recommendations based on the Polish Diabetes Association (PTD) guidelines. ${ }^{5}$ Self-care is particularly important in patients with diabetes, and comprises multiple components such as diet, exercise, reduction of alcohol consumption, symptom monitoring, recognizing and managing symptoms, foot self-care, and adherence to pharmaceutical treatment. ${ }^{10}$ Active participation in the treatment process helps patients consciously manage their health. However, such participation requires cognitive skills such as learning, perceiving, and interpreting.

In patients with diabetes, older age is associated with limitations resulting from the patient's progressive disability, impaired vision and hearing, poorer drug metabolism, and impaired cognitive functions. Diabetes is listed among the risk factors for cognitive impairment due to such processes as chronic hyperglycemia or hypoglycemia, insulin resistance or hyperinsulinemia, oxidative stress, and the accumulation of beta-amyloid in the brain. ${ }^{11}$

The impact of cognitive dysfunction on hypoglycaemia is the most critical because of its critical consequences in the older patients with diabetes. There is a two-way relationship between dementia and risk of hypoglycaemia. In patients with dementia, the risk of subsequent episodes of hypoglycaemia was three times higher. The relationship between cognitive dysfunction and the risk of hypoglycaemia is evident in patients with both type 1 and type 2 diabetes. ${ }^{12-14}$ Elderly patients with diabetes have a significantly increased prevalence of dementia and mild cognitive impairment compared with people of similar age without diabetes. Long-term history of diabetes increases the risk of vascular dementia and cognitive impairment, while unstable glycemia affects concentration, attention, and memory. Diabetes is associated with a $60 \%$ higher risk of dementia overall, a $120 \%$ higher risk of vascular dementia in women, and a $70 \%$ higher risk of vascular dementia in men. ${ }^{15}$ In patients with diabetes, cognitive function deteriorates by approx. $20 \%$ within 20 years. ${ }^{16}$

Cognitive problems in patients with diabetes involve attention, executive function, learning and memory, psychomotor drive, visual and spatial skills, language, and perception. ${ }^{17}$ Areas that are particularly strongly affected in patients with diabetes include verbal memory and psychomotor function. ${ }^{18}$ Tasks related to diabetes selfmanagement involve multiple cognitive skills and processes, such as memory, attention, planning, and calculating. ${ }^{16}$ Cognitive impairment has the potential to interfere with blood glucose self-monitoring and achieving glycemic control. ${ }^{19}$ Impaired cognitive function can threaten the patient's ability to perform self-monitoring.

High rates of unidentified cognitive deficits in older adults suggest that it is important to screen periodically for cognitive dysfunction. Such dysfunction makes it difficult for patients to perform complex self-care tasks, such as blood glucose monitoring, adjusting insulin doses, or appropriately managing the timing and content of diet. In older patients with cognitive dysfunction, regimens should be simplified, caregivers involved, and the occurrence of hypoglycemia carefully assessed.

The topic of cognitive dysfunction in patients with diabetes is well documented in the literature, and there is an increasing number of reports focusing on assessing selfcare capabilities of patients with diabetes. Unfortunately, there are only a few available papers evaluating the relationship between cognitive impairment in patients with diabetes and their self-care capabilities. Thus, it seems important to pursue investigations into the relationship between cognitive impairment and the self-care and adherence to treatment of patients with diabetes.

The objectives of the present study were: to assess cognitive deficits and the level of self-care in elderly patients with diabetes, to identify correlations between cognitive deficits and self-care, and to determine which variables influence self-care behaviors and cognitive deficits. 


\section{Patients and Methods}

The present study has a cross-sectional and observational design. The study used a closed-ended standardized survey and 1-on-1 interviews.

Patients with a clinically confirmed type 2 diabetes diagnosis, hospitalized in an internal medicine department, were recruited. Inclusion criteria were as follows: clinical diagnosis of type 2 diabetes as per the PTD guidelines, age over 18 years, treatment with oral hypoglycemic agents and/or insulin for at least 6 months, and written informed consent to participate. ${ }^{5}$ Exclusion criteria were as follows: exacerbation of another chronic condition (chronic heart failure-NYHA-IV, ischemic heart disease - CCS-IV, neoplastic disease, acute respiratory disease), inability to complete the questionnaire, lack of consent to participate.

Patients admitted to the department for diagnostic tests to follow up on the previously planned diabetes treatment were recruited for the study on their first day of hospitalization. Their eligibility was determined by trained professionals. Patients were selected by a panel consisting of a physician and a nurse-specialist in the field of internal medicine. A study protocol was prepared for the purpose of the study so that the personnel could collect data in the same way. Respondents answered all questions directly, based on their last 4 weeks of treatment. The personnel were informed about the aim of the study. The research team included a physician specializing in internal medicine, and two diabetes nurses responsible for cognitive function assessment and self-care survey distribution. Socio-demographic and clinical data were obtained from the patients' medical records, with their consent.

The examined patients did not take other medicines in addition to insulin injections. Hypertension was diagnosed by physician according to the European Society of Cardiology guidelines. ${ }^{20}$ The patients were tested for HbAlc from venous blood. All patients measured their glycemia with a glucometer (patients did not use FGM/ CGM). Patients were administered insulin using only personal insulin pens, patients undergoing intensive insulin therapy in acute conditions were excluded from the study.

In the study period (November 2019-March 2020), 278 patients with type 2 diabetes diagnosed in accordance with the PTD criteria were hospitalized in the department. ${ }^{5}$ In this group, 65 patients did not meet the inclusion criteria, and 12 refused to participate. Therefore, 201 patients were included in the study and received surveys; however, during the study, 32 patients dropped out without providing a reason or did not complete the survey correctly. The final group included 169 patients. All patients were informed about the study course and methods, and about the possibility of withdrawing from the study at any time. All patients provided their written informed consent to participate in the anonymous survey.

\section{Questionnaires}

- The SCODI (Self-Care of Diabetes Inventory) questionnaire, which is used to evaluate self-care in diabetes, is an instrument comprising 40 items (rated on a 5-item Likert scale), grouped into four dimensions: self-care maintenance (comprises health-promoting exercise behaviours, disease prevention behaviours, health-promoting behaviours and illness-related behaviours), self-care monitoring (comprises body listening and symptom recognition), self-care management (autonomous self-care management behaviours and consultative self-care management behaviours, blood glucose control), and self-care confidence (comprises task-specific self-care confidence and persistence of self-care confidence). Each of the four parts is scored separately and standardized to a $0-100$ scale, with higher scores indicating better self-care. ${ }^{9}$ In the study, the Polish version of the SCODI was used. ${ }^{21}$ The Polish version of the questionnaire is available at: https://self-care-measures.com/project/patient-versionscodi-polish/

- The MMSE (Mini-Mental State Examination) is used to assess a patient's cognitive status: orientation to time and place, registration, attention and calculation, recall, language, repetition, following complex commands (provided orally or in writing), and visuospatial capabilities. The total score may range between 0 and 30 points, with lower scores indicating more cognitive impairment and more severe dementia. Scores of 27-30 points indicate no cognitive impairment, those from 26 to 24 points indicate mild cognitive impairment without dementia, and scores of and below 23 points indicate dementia. ${ }^{22}$

- The ARMS (Adherence to Refills and Medications Scale) consists of 12 statements in two subscales: adherence to drug recommendations and adherence to prescription refills. Each item can be rated "(1) never", "(2) rarely", "(3) often", or "(4) most of the time". The responses are shown on a Likert scale. To obtain the overall adherence assessment, points from all 12 items are summarized, for a total score of 12-48 points. The lower the score, the better the adherence. $^{23}$ 


\section{Statistical Analysis}

In statistical analysis, non-parametric tests were used to compare the results obtained. Quantitative variables were presented as median and quartile values. For comparing median values in two data series, the Mann-Whitney test was used. For comparing more data series, we used the Kruskal-Wallis test and multiple comparisons. Multiplefactor analysis was performed using multiple logistic regression. To select the best regression models, we used backward stepwise regression. Results were considered statistically significant at $\mathrm{p}<0.05$. Calculations were performed using the Polish version of the Statistica 12.5 software package (StatSoft, Tulsa, USA).

The patients were broken down into 3 groups by MMSE scores: group I-normal cognitive function (MMSE: 30-27 points), group II-cognitive impairment without dementia (MMSE: 26-24 points), group III-cognitive impairment and dementia (MMSE: $\leq 23$ points). Further analyses were carried out depending on the cognitive function assessment result.

\section{Ethical Consideration}

The study was approved by the Bioethics Committee at the Medical University in Wroclaw (approval no. 590/2016) and was conducted in accordance with the Helsinki Declaration and the principles of good clinical practice, with respect for the rights and dignity of the participants. All participants provided written informed consent.

\section{Results}

\section{Patients' Socio-Demographic Characteristics}

Patients with cognitive impairment were more likely to be older, professionally inactive, have completed vocational education, and live in rural areas than those with an MMSE score in the normal range: $70.8 \pm 7.3$ vs $64.5 \pm 6.9$, $84.4 \%$ vs $53.4 \%, 34.4 \%$ vs $19.2 \%$, and $56.2 \%$ vs $15.1 \%$, respectively (Table 1 ).

\section{Patients' Clinical Characteristics}

Cognitively impaired patients were more likely to be treated with more drugs, have longer duration of diabetes, and have more hyperglycemic episodes $(8.19 \pm 2.42$ vs 5.84 $\pm 3.45,15.12 \pm 8.71$ vs $5.0 \pm 18.51,93.6 \%$ vs $68.5 \%$ ) than those with intact cognitive function. They also had less frequent follow-up diabetologist visits - every 6 months (93.6\% vs 43.8\%). (Table 2) Moreover, more patients in the cognitively impaired group had nervous system diseases (21.8\% vs 5.5\%) (Table 2$)$. The group with cognitive impairment included the fewest patients treated with insulin (46,9\% vs $49.3 \%)$.

Table I Socio-Demographic Characteristics of the Patients with Diabetes Studied, Broken Down by MMSE Scores

\begin{tabular}{|c|c|c|c|c|c|c|}
\hline \multicolumn{2}{|c|}{ Parameters } & \multicolumn{4}{|l|}{ MMSE } & \multirow{3}{*}{$\begin{array}{l}\mathbf{p} \\
0.003^{*}\end{array}$} \\
\hline & & \multirow{2}{*}{$\begin{array}{l}\begin{array}{l}\text { Normal } \\
(\mathbf{N}=73)\end{array} \\
64.5 \pm 6.9\end{array}$} & \multirow{2}{*}{$\begin{array}{l}\begin{array}{l}\text { Cognitive Impairment } \\
\text { without Dementia }(\mathbf{N}=64)\end{array} \\
65.6 \pm 5.9\end{array}$} & \multirow{2}{*}{$\begin{array}{l}\text { Cognitive Impairment } \\
\text { with Dementia (N=32) } \\
70.8 \pm 7.3\end{array}$} & \multirow{2}{*}{$\begin{array}{l}\begin{array}{l}\text { Total } \\
(\mathrm{N}=169)\end{array} \\
65.33 \pm 9.49\end{array}$} & \\
\hline Age [years] & $\mathrm{Me} \pm \mathrm{SD}$ & & & & & \\
\hline Gender & $\begin{array}{l}\text { Female } \\
\text { Male }\end{array}$ & $\begin{array}{l}39(53.4 \%) \\
34(46.6 \%)\end{array}$ & $\begin{array}{l}36(56.2 \%) \\
28(43.8 \%)\end{array}$ & $\begin{array}{l}15(46.9 \%) \\
17(53.1 \%)\end{array}$ & $\begin{array}{l}80(47.3 \%) \\
89(52.7 \%)\end{array}$ & 0.506 \\
\hline Residence & $\begin{array}{l}\text { Urban } \\
\text { Rural }\end{array}$ & $\begin{array}{l}62(84.9 \%) \\
\text { II (15.1\%) }\end{array}$ & $\begin{array}{l}37(57.8 \%) \\
27(42.2 \%)\end{array}$ & $\begin{array}{l}14(43.8 \%) \\
18(56.2 \%)\end{array}$ & $\begin{array}{l}110(65.1 \%) \\
59(34.9 \%)\end{array}$ & $0.002^{*}$ \\
\hline Education & $\begin{array}{l}\text { Primary } \\
\text { Vocational } \\
\text { High school } \\
\text { College/University }\end{array}$ & $\begin{array}{l}\text { I (I.4\%) } \\
14(19.2 \%) \\
30(41.1 \%) \\
28(38.3 \%)\end{array}$ & $\begin{array}{l}2(3.1 \%) \\
28(43.8 \%) \\
23(35.9 \%) \\
11(17.2 \%)\end{array}$ & $\begin{array}{l}8(25.0 \%) \\
\text { II }(34.4 \%) \\
\text { II (34.4\%) } \\
2(6.2 \%)\end{array}$ & $\begin{array}{l}\text { II (6.5\%) } \\
59(34.9 \%) \\
66(39.1 \%) \\
33(19.5 \%)\end{array}$ & $0.046 *$ \\
\hline $\begin{array}{l}\text { Professional } \\
\text { status }\end{array}$ & $\begin{array}{l}\text { Professionally active } \\
\text { Retirement/pensioner }\end{array}$ & $\begin{array}{l}34(46.6 \%) \\
39(53.4 \%)\end{array}$ & $\begin{array}{l}22(34.4 \%) \\
42(65.6 \%)\end{array}$ & $\begin{array}{l}5(15.6 \%) \\
27(84.4 \%)\end{array}$ & $\begin{array}{l}51(30.2 \%) \\
118(69.8 \%)\end{array}$ & $0.018^{*}$ \\
\hline $\begin{array}{l}\text { Marital } \\
\text { status }\end{array}$ & $\begin{array}{l}\text { Unmarried } \\
\text { Married }\end{array}$ & $\begin{array}{l}51(69.9 \%) \\
22(30.1 \%)\end{array}$ & $\begin{array}{l}44 \text { (68.8\%) } \\
20(31.2 \%)\end{array}$ & $\begin{array}{l}20(62.5 \%) \\
12(37.5 \%)\end{array}$ & $\begin{array}{l}113(66.9 \%) \\
56(33.1 \%)\end{array}$ & 0.829 \\
\hline
\end{tabular}

Notes: $\mathrm{p}-$ Mann-Whitney test for quantitative variables, chi-squared test or Fisher's exact test for qualitative variables; $*$ Statistically significant difference ( $<<0.05$ ). Abbreviations: me, mean; SD, standard deviation; MMSE, Mini-Mental State Examination. 
Table 2 Clinical Characteristics of the Patients_for the Entire Group and Broken Down by Cognitive Function

\begin{tabular}{|c|c|c|c|c|c|c|}
\hline \multicolumn{2}{|l|}{ Parameters } & \multicolumn{4}{|l|}{ MMSE } & \multirow{2}{*}{\begin{tabular}{|l}
$\mathbf{p}$ \\
0.853
\end{tabular}} \\
\hline & & $\begin{array}{l}\text { Normal } \\
(\mathbf{N}=73) \\
52(71.2 \%)\end{array}$ & \multirow{2}{*}{$\begin{array}{l}\begin{array}{l}\text { Cognitive } \\
\text { Impairment } \\
\text { without } \\
\text { Dementia } \\
(\mathbf{N}=64)\end{array} \\
46(71.8 \%) \\
16(25.0 \%) \\
11(17.2 \%) \\
7(10.9 \%) \\
2(3.1 \%)\end{array}$} & \multirow{2}{*}{$\begin{array}{l}\text { Cognitive } \\
\text { Impairment } \\
\text { with Dementia } \\
(\mathbf{N}=32) \\
25(78.1 \%) \\
5(15.6 \%) \\
2(6.3 \%) \\
9(28.1 \%) \\
7(21.8 \%)\end{array}$} & \multirow{2}{*}{$\begin{array}{l}\text { Total }(\mathbf{N}=169) \\
\\
123(72.8 \%) \\
39(23.1 \%) \\
22(13.0 \%) \\
23(13.6 \%) \\
13(7.7 \%)\end{array}$} & \\
\hline Comorbidities & $\begin{array}{l}\text { Hypertension according to ESC } \\
\text { Ischemic heart disease } \\
\text { Atherosclerosis } \\
\text { Obesity (BMI } \geq 30 \text { ) } \\
\text { Nervous system diseases }\end{array}$ & $\begin{array}{l}52(71.2 \%) \\
18(24.7 \%) \\
9(12.3 \%) \\
7(9.6 \%) \\
4(5.5 \%)\end{array}$ & & & & $\begin{array}{l}0.853 \\
0.767 \\
0.508 \\
0.152 \\
0.026^{*}\end{array}$ \\
\hline $\begin{array}{l}\text { Duration of diabetes } \\
\text { [years] }\end{array}$ & $\mathrm{Me} \pm \mathrm{SD}$ & $5.0 \pm|8.5|$ & $11.0 \pm 7.84$ & $|5| 2 \pm 8.7 \mid$. & $11.65 \pm 13.86$ & $0.003^{*}$ \\
\hline $\begin{array}{l}\text { Number of drugs taken } \\
\text { per day }\end{array}$ & $\mathrm{Me} \pm \mathrm{SD}$ & $5.84 \pm 3.45$ & $6.55 \pm 3.23$ & $8.19 \pm 2.42$ & $6.49 \pm 3.3$ & $0.001 *$ \\
\hline $\begin{array}{l}\text { Last glucose level [mg/dl] } \\
\text { (measured from capillary } \\
\text { blood with a glucometer) }\end{array}$ & $\operatorname{Me}(\min -\max )$ & $138(|20-15|)$ & $140(128-173)$ & $145(120-154)$ & $145(75-680)$ & 0.066 \\
\hline $\begin{array}{l}\text { Last HbAlc (measured } \\
\text { from venous blood) }\end{array}$ & $\operatorname{Me}(\min -\max )$ & $6.3(5.7-7.1)$ & $5.9(5.8-7.4)$ & $6.1(5.6-6.6)$ & $6.9(5.2-14.9)$ & 0.092 \\
\hline Early complications & $\begin{array}{l}\text { Hyperglycemia } \\
\text { Hypoglycemia }\end{array}$ & $\begin{array}{l}50(68.5 \%) \\
23(31.5 \%)\end{array}$ & $\begin{array}{l}50(78.1 \%) \\
14(21.9 \%)\end{array}$ & $\begin{array}{l}30(93.6 \%) \\
4(12.5 \%)\end{array}$ & $\begin{array}{l}116(68.6 \%) \\
32(18.9 \%)\end{array}$ & $0.028^{*}$ \\
\hline $\begin{array}{l}\text { Follow-up diabetologist } \\
\text { visits }\end{array}$ & $\begin{array}{l}\text { Once a month } \\
\text { Every } 3 \text { months. } \\
\text { Every } 6 \text { months. } \\
\text { No }\end{array}$ & $\begin{array}{l}3(4.2 \%) \\
36(49.3 \%) \\
32(43.8 \%) \\
2(2.7 \%)\end{array}$ & $\begin{array}{l}2(3.1 \%) \\
14(21.9 \%) \\
44(68.8 \%) \\
4(6.2 \%)\end{array}$ & $\begin{array}{l}0(0.0 \%) \\
0(0.0 \%) \\
30(93.6 \%) \\
2(6.3 \%)\end{array}$ & $\begin{array}{l}6(3.6 \%) \\
97(57.4 \%) \\
56(33.1 \%) \\
10(5.9 \%)\end{array}$ & $0.019 *$ \\
\hline Treatment & $\begin{array}{l}\text { Pharmaceutical treatment } \\
\text { Insulin therapy (with insulin } \\
\text { pens) } \\
\text { Combination therapy (insulin + } \\
\text { drugs) }\end{array}$ & $\begin{array}{l}52(71.2 \%) \\
36(49.3 \%) \\
12(16.4 \%)\end{array}$ & $\begin{array}{l}38(59.4 \%) \\
39(60.9 \%) \\
7(10.9 \%)\end{array}$ & $\begin{array}{l}\text { II (34.4\%) } \\
15(46.9 \%) \\
5(15.6 \%)\end{array}$ & $\begin{array}{l}79(46.8 \%) \\
67(39.6 \%) \\
23(13.6 \%)\end{array}$ & $0.015^{*}$ \\
\hline $\begin{array}{l}\text { Self-Care of Diabetes } \\
\text { Index (SCODI) }\end{array}$ & $\begin{array}{l}\text { SCODI A: Self-care maintenance } \\
\text { SCODI B: Self-care monitoring } \\
\text { SCODI C: Self-care management } \\
\text { SCODI D: Self-care confidence }\end{array}$ & $\begin{array}{l}75.0(67-85) \\
84.4(63-91) \\
56.3(47-72) \\
86.4(68-98)\end{array}$ & $\begin{array}{l}72.9(69-82) \\
75.0(65-88) \\
54.7(44-63) \\
84.1(77-95)\end{array}$ & $\begin{array}{l}57.3(46-70) \\
50.0(48-79) \\
43.8(35-47) \\
61.4(50-71)\end{array}$ & $\begin{array}{l}72.9(64.6-83.3) \\
71.9(56.3-90.6) \\
53.1(43.8-62.5) \\
79.5(67.0-95.5)\end{array}$ & $\begin{array}{l}<0.00 \text { I* }^{*} \\
0.006^{*} \\
0.002^{*} \\
<0.00 \text { I }^{*}\end{array}$ \\
\hline ARMS & $\begin{array}{l}\text { Pills }(n=101) \\
\text { Insulin }(n=95)\end{array}$ & $\begin{array}{l}18.5 \pm 7.10 \\
20.28 \pm 7.16\end{array}$ & $\begin{array}{l}17.26 \pm 4.75 \\
17.95 \pm 2.95\end{array}$ & $\begin{array}{l}17.65 \pm 4.85 \\
20.37 \pm 5.26\end{array}$ & $\begin{array}{l}18.04 \pm 6.08 \\
19.55 \pm 5.59\end{array}$ & $\begin{array}{l}0.350 \\
0.019 *\end{array}$ \\
\hline
\end{tabular}

Notes: $p$-Mann-Whitney test for quantitative variables, chi-squared test or Fisher's exact test for qualitative variables; $*$ Statistically significant difference ( $<<0.05$ ). Abbreviations: HbAlc, glycated haemoglobin; Me, mean; SD, standard deviation; MMSE, Mini-Mental State Examination; BMI, body mass index; HbAIc, glycated hemoglobin; ARMS, the Adherence to Refills and Medications Scale; ESC, the European Society of Cardiology.

\section{Self-Care Characteristics Depending on MMSE Scores}

In the study group, there were statistically significant differences in terms of self-care between the subgroups (Table 2). In patients with cognitive impairment, SCODI scores were significantly lower in all domains (self-care maintenance: 57.3 , self-care monitoring: 50.0 , self-care management: 43.8, self-care confidence: 61.4 ).

Both patients with impaired and with normal cognitive function scored the highest for self-care confidence, and the lowest for self-care management. The statistically significant differences were found between groups of patients treated with insulin. Patients with cognitive impairment 
and dementia treated with insulin had the lowest adherence score $(20.37 \pm 5.26)$.

\section{Association Between Cognitive Function (MMSE) and Self-Care (SCODI)}

Correlation analysis for the impact of cognitive function on self-care demonstrated a significant positive correlation between MMSE scores $(\mathrm{p}<0.05, \mathrm{r}>0)$ and all SCODI subscales. Higher MMSE scores were associated with better self-care in all domains: SCODI A: $r=0.252$, SCODI B: $r=0.244$, SCODI C: $r=0.181$, SCODI D: $\mathrm{r}=0.28$ (Table 3).

An analysis was also performed for the areas assessed using the MMSE questionnaire and SCODI domains. Spearman correlation analysis showed a significant and positive correlation between the selfcare maintenance domain and the following MMSE areas: recall $(\mathrm{r}=0.342, \mathrm{p}<0.001)$, writing $(\mathrm{r}=0.246$, $\mathrm{p}=0.001)$, and constructive praxis $(\mathrm{r}=0.238, \mathrm{p}=0.002)$ (Figure 1). Self-care monitoring was significantly positively correlated with: attention and calculation $(\mathrm{r}=0.179$, $\mathrm{p}=0.02)$, recall $(\mathrm{r}=0.213, \mathrm{p}=0.005)$, writing $(\mathrm{r}=0.273$, $\mathrm{p}<0.001)$, and constructive praxis $(\mathrm{r}=0.213, \mathrm{p}=0.005)$. Self-control management was significantly positively correlated with orientation to time and place $(\mathrm{r}=0.238$, $\mathrm{p}=0.002$ ). There was also a significant and positive correlation between self-care confidence and attention and calculation $(\mathrm{r}=0.197, \mathrm{p}=0.01)$, recall $(\mathrm{r}=0.223, \mathrm{p}-0.004)$, writing $(\mathrm{r}=0.275, \mathrm{p}<0.001)$, and constructive praxis $(\mathrm{r}=0.241, \mathrm{p}=0.002)$.

\section{Linear Regression Analysis}

Our linear regression analysis demonstrated that the total MMSE score and normal cognitive function are independent predictors of all SCODI subscales $(\mathrm{p}<0.05)$. Each

Table 3 Correlation Analysis Results for Self-Care Level and Cognitive Function

\begin{tabular}{|l|l|}
\hline \multirow{2}{*}{ SCODI } & MMSE \\
\cline { 2 - 2 } & $\begin{array}{l}\text { Spearman's Rank } \\
\text { Correlation Coefficient }\end{array}$ \\
\hline SCODI A: Self-care maintenance & $r=0.252, p=0.00 I^{*}$ \\
SCODI B: Self-care monitoring & $r=0.244, p=0.00 I^{*}$ \\
SCODI C: Self-care management & $r=0.18 I, p=0.019^{*}$ \\
SCODI D: Self-care confidence & $r=0.28, p<0.00 I^{*}$ \\
\hline
\end{tabular}

Note: *Statistically significant correlation $(p<0.05)$.

Abbreviations: SCODI, Self-Care of Diabetes Inventory; MMSE, Mini-Mental State Examination.

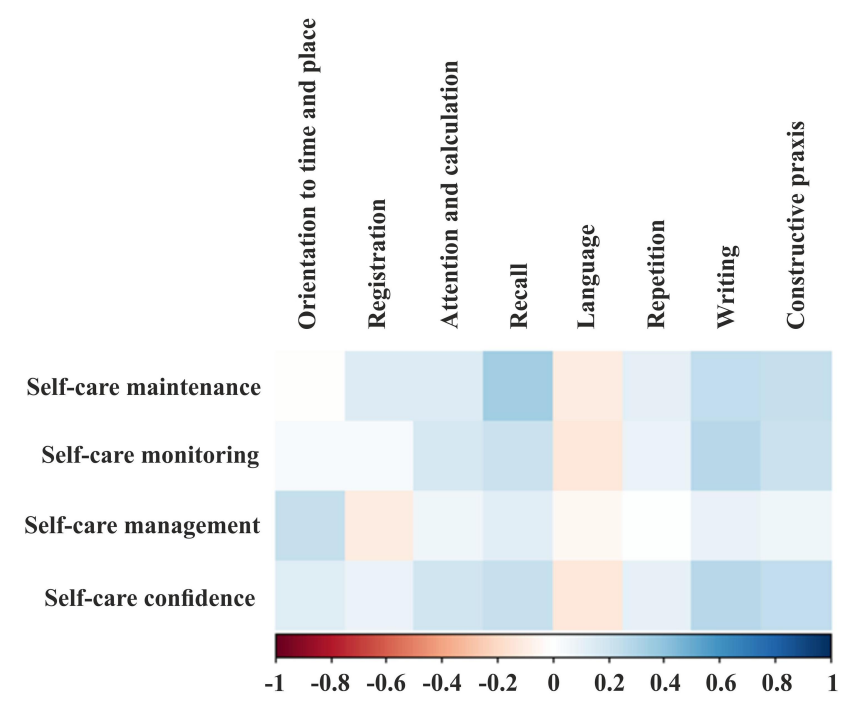

Figure I Heat map of correlations between self-care level (SCODI) and cognitive function (MMSE).

additional point in the MMSE increases the score for selfcare maintenance by 1.108 points on average, for self-care monitoring by 1.384 points, for self-care management by 1.184 points, and for self-care confidence by 2.269 points (Table 4).

In addition, the linear regression model demonstrated significant $(p<0.05)$ independent predictors for SCODI domains: the "recall" MMSE domain for self-care maintenance $(\mathrm{r}=4.359, \mathrm{p}=0.003)$, and "writing" for self-care monitoring $(\mathrm{r}=30.862, \mathrm{p}=0.018)$.

\section{Discussion}

Despite researchers' considerable interest in type 2 diabetes patients, the relationship between cognitive function and self-care in this patient group is not yet sufficiently documented. Our study is the first in Poland and one of the few in the world to investigate associations between cognitive impairment and the level of self-care and adherence to pharmaceutical treatment in elderly patients with type 2 diabetes.

In our study, normal cognitive function was associated with better self-care in all SCODI domains, and each additional point in the MMSE significantly improved selfcare capabilities as measured by all SCODI domains. These findings are in line with those reported by Thabit et al, where cognitive function was found to have a significant impact on self-care in patients with diabetes. ${ }^{19}$ In turn, results published by Sinclair et al showed that patients with cognitive impairment considerably less often performed diabetes self-management and 


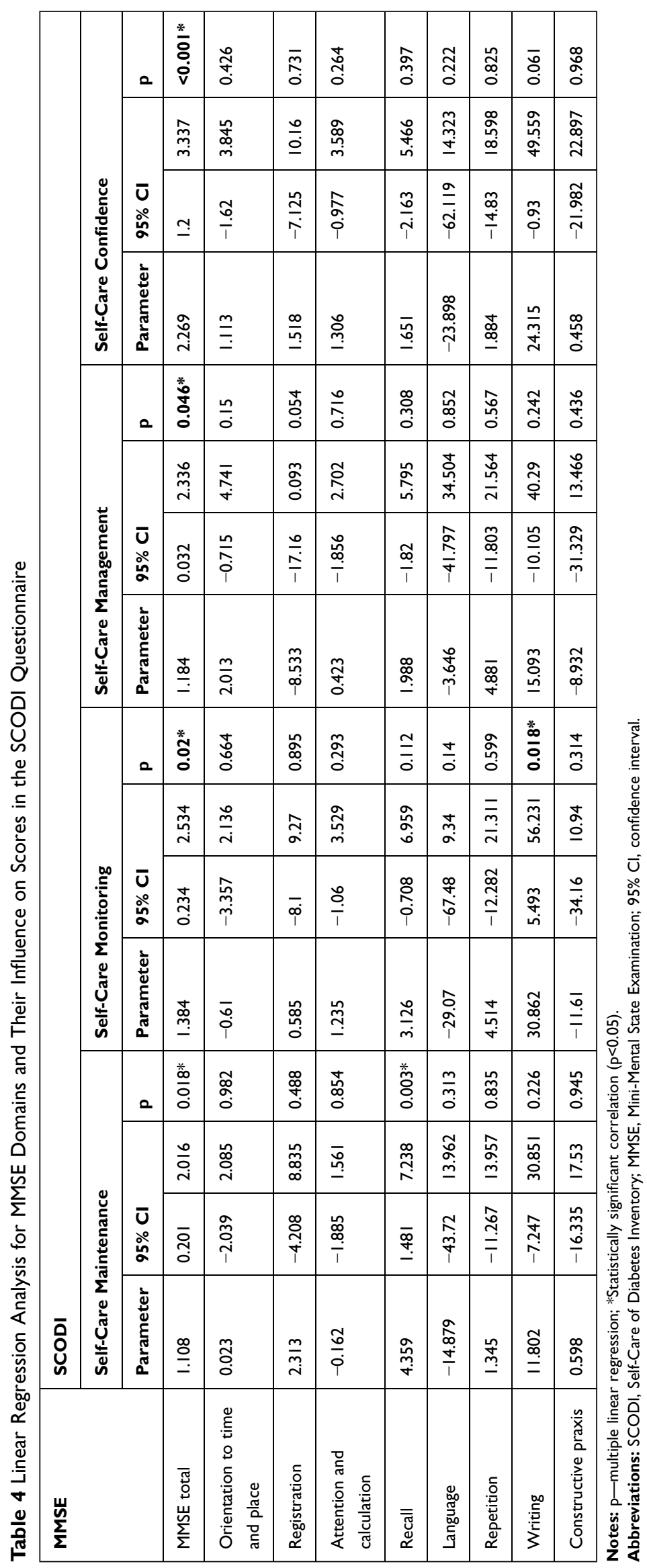


self-monitoring compared to those with normal MMSE scores. ${ }^{24}$ Similar results were obtained in a population of Polish patients with diabetes, where the respondents were most likely to have difficulties in self-care management $(54.65 \pm 22.98) .{ }^{21}$ Additionally, the present study demonstrated the impact of cognitive function on the self-care capabilities of patients with type 2 diabetes. Feil et al reported that respondents with impaired cognitive function were more likely to experience problems with adherence to treatment and self-care. ${ }^{25}$ Trimble et al showed that patients with abnormal clock drawing test results were significantly more likely to have difficulty learning how to perform a sham insulin injection. ${ }^{26}$ As reported by Sinclair et al, compared to patients with diabetes with no cognitive impairment, those with MMSE scores below 23 were significantly less involved in their treatment and symptom monitoring. ${ }^{24}$ Low MMSE scores have also been associated with missed clinic appointments and poorer adherence.

In our study, an analysis of patients' sociodemographic characteristics including cognitive status demonstrated that patients with MMSE scores $\leq 18$ tended to be older, professionally inactive, have completed vocational education, and live in rural areas. The association between socio-demographic and mental ability has been documented in the literature. ${ }^{24,27}$ In line with the engagement hypothesis, individuals who consistently place significant demands on their intellectual resources (by engaging in multiple complex choices and decisionmaking in the face of ill-defined problems) are likely to preserve or even improve their cognitive capacity. ${ }^{28}$ It is known that educated and professionally active individuals are more active intellectually, which may have a beneficial effect on the maintenance of cognitive function. ${ }^{28}$ This is associated with the cognitive reserve, which is greater in individuals who are more educated and who continuously engage in mental skill and memory training. In individuals with a small cognitive reserve (older, less educated, professionally inactive), each factor that weakens cognitive potential produces a more rapid and severe deterioration. In our study, patients with cognitive impairment were older than those with a normal cognitive status. This is consistent with literature reports. An analysis of 40,000 patients with diabetes showed that environmental factors such as living alone and living in a rural environment significantly affect the development of cognitive disorders and the quality of metabolic control in diabetes. ${ }^{27}$ In older patients with type 2 diabetes, cognitive impairment is associated with poor self-management, a greater need for assistance in care, and an increased risk of hospitalization. $^{24}$

In our study, there was an association between cognitive impairment and patients' clinical characteristics. Cognitively impaired patients required more drugs, had a longer duration of diabetes, had more frequent hyperglycemic episodes, and had less frequent diabetic follow-ups than those with a normal cognitive status. In the study by Ott et al, type 2 diabetes was found to significantly increase the risk of all causes of dementia, especially in patients treated with insulin (ie, likely to have more severe disease) at baseline. ${ }^{29}$ In our study, there were no differences in terms of adherence to oral hypoglycemic therapy between patients broken down by MMSE, but adherence to insulin therapy did differ. Those with cognitive impairment showed the poorest adherence to insulin therapy. Arvanatakis et al suggest that insulin therapy has an adverse impact on the prevalence of cognitive impairment in patients with diabetes. ${ }^{30}$ Hewitt et al showed that patients with cognitive impairment who were treated with insulin are less likely to know what to do if they become hypoglycemic, and how to dose their insulin correctly. ${ }^{31}$ In the present study, adherence to treatment was poor in the cognitively impaired group, and thus, hyperglycemia was more frequent in those patients.

Patients with cognitive impairment had been diabetic longer those with a normal cognitive status. Duration of diabetes is associated with a greater prevalence of cognitive impairment. ${ }^{11,16}$ In their study, Compeán-Ortiz et al demonstrated that duration of diabetes exceeding 10 years is associated with at least a $55 \%$ greater risk of severe cognitive impairment. ${ }^{32}$ Cognitive function was also poorer in patients treated with multiple medications. In the available papers, the number of comorbidities was also associated with an increased risk of cognitive impairment. ${ }^{32}$ In the study by Snyder et al, nearly all patients had at least one comorbidity. The most common comorbidity was hyperlipidemia, followed by high blood pressure; notably, both have a proven link to cognitive impairment. ${ }^{33}$ Additionally, long-term history of diabetes increases the risk of vascular dementia and cognitive impairment, while unstable glycemia affects concentration, attention, and memory.

There is an ongoing discussion in the literature regarding the relationship between glycated hemoglobin levels and cognitive function. In our study, there was no association between the two, though there are reports suggesting 
that glycated hemoglobin levels may be related to cognitive function. Nonetheless, many authors consider this parameter significant only for metabolic control of diabetes, not for cognitive function. Executive function impairment was significantly associated with higher glycated hemoglobin levels. In the study by Nguyen et al, the correlation with $\mathrm{HbAlc}$ became insignificant when all diabetes control risk factors were included in the regression analysis. ${ }^{34}$ Both Thabit et al and Rosen et al showed no correlation between $\mathrm{HbAlc}$ levels and any cognitive variable. $^{34,35}$ Our study did not confirm any impact of glycated hemoglobin levels on cognitive status. Still, normal glycated hemoglobin levels can also be achieved when glycemia is highly unstable.

A detailed analysis of the components of cognitive function and self-care capabilities confirmed a relationship between recall and writing on the one hand, and self-care monitoring and maintenance on the other.

In the study by Kazlauskaite et al, the results of the Digit Symbol Coding Test (the memory component of the WAIS-III) were significantly correlated with inaccuracies in recording and reporting blood glucose levels. ${ }^{36}$ Ghisletta et al reported that activities such as reading books or playing games are associated with changes in perceptual speed, while other forms of engagement (eg, physical, social, and religious activities) are not. Conversely, activities associated with a low level of cognitive stimulation, such as watching television, were linked to an increased risk of cognitive impairment. ${ }^{37}$ Patients who notice that they have memory problems rarely seek effective ways to improve it, and tend to demonstrate poor self-care and adherence to treatment. Teixeira et al confirmed an association between diabetes and cognitive performance, mainly in the domains of memory, attention, concentration, psychomotor speed and executive function. ${ }^{38}$ Hewitt et al reported that insulin-dependent older persons with cognitive impairment had poorer knowledge about managing hypoglycemia and medications than did patients without impairment. ${ }^{31}$ Patients with poor glycemic control lacked understanding of basic self-care (mechanisms of medications, concepts of glucose monitoring, symptom detection, role of exercise, dietary instructions, and behaviorlifestyle adjustment), and had difficulty detecting and solving problems. ${ }^{39}$ In a study by Lippa and Klein many individuals could detect symptoms of hyper- or hypoglycemia, they often lacked the ability to correct for these states. Individuals with good glycemic control regularly monitored their diets and could effectively identify and manage episodes of hypo- and hyperglycemia. ${ }^{39}$ In a study by Caller et al, patients with impaired memory had difficulties in developing an approach to solving diabetes-related problems. ${ }^{40}$ Asimakopoulou and Hampson confirmed an association between patient-reported memory problems and a low number of strategies for solving problems in selfmanagement. ${ }^{41}$

\section{Conclusion}

1. In this elderly type 2 diabetes population, and using only one test to verify the cognitive function, self-care management was worse in terms of self-care management (blood glucose control).

2. Cognitive function components are independent determinants of self-care in patients with type 2 diabetes. Recall is an independent predictor of self-care maintenance, and writing a predictor of self-care monitoring.

\section{Study Limitations}

We are well aware of the potential limitations of this study. The most important one is the fact that the study sample was relatively small and recruited from a single center. Another is that cognitive function was only assessed using a survey. The study is also limited by the lack of psychosocial determinants evaluation (religion, faith, family support or assistance and depression), as this disorder has been reported in the literature as a potential contributor to cognitive impairment and poor self-care. The last limitation is the study design (cross-sectional study) which precluded understanding whether understanding the rate of decline of cognition, and whether poor self-care and sustained levels of poor metabolic outcomes including glycemic control actually preceding the onset and progression of cognitive impairment in patients with DM.

\section{Implications for Practice}

High rates of unidentified cognitive deficits in older adults suggest that it is important to screen periodically for cognitive dysfunction. The identification of cognitive dysfunction and modification of treatment regimens to accommodate it in older patients is important for successful diabetes management. Cognitive function should be assessed before each educational intervention, and if cognitive impairment is found, the family should be present during educational sessions and involved in the treatment 
and care process. In the future, a study should be considered using a neurocognitive test battery, which would make it possible to investigate different aspects of cognitive function and self-care. There is a need for future research to assess the effectiveness of educational interventions in increasing self-care levels in diabetic patients.

\section{Acknowledgments}

The authors declare no conflict of interest. All co-authors have seen and agree with the contents of the manuscript. This work was prepared as part of the project financed from funds granted by the Wroclaw Medical University, project number STM.E025.20.170. The funder was not involved in the study design, collection, analysis, interpretation of data, in the writing of this article, nor in the decision to submit it for publication.

\section{Disclosure}

Natalia Świątoniowska-Lonc and Beata JankowskaPolańska report grants from Wroclaw Medical University, outside the submitted work. The authors report no other conflicts of interest in this work.

\section{References}

1. Diabetes; 2021. Available from: https://www.who.int/news-room/factsheets/detail/diabetes. Accessed June 7, 2020.

2. CDC Division of Diabetes Translation, National Center for Chronic Disease and Health Promotion. Incidence of diagnosed diabetes per 1000 population aged 18-79 years, by age, United States, 1980-2010; 2021. Available from: http://www.cdc.gov/diabetes/statistics/inci dence/fig3.htm. Accessed June 7, 2020.

3. NFZ o Zdrowiu Cukrzyca; 2021. Available from: https://www.google.com/ url?sa=t\&rct=j\&q=\&esrc $=$ s\&source $=$ web\&cd $=\&$ cad $=$ rja\&uact $=8 \& v e d=$ 2ahUKEwio_OT3w4btAhXQtYsKHXyZAKkQFjAAegQIBhAC\&url= https $\% 3 \mathrm{~A} \% 2 \mathrm{~F} \% 2 \mathrm{Fzdrowedane.nfz.gov.pl} \% 2 \mathrm{Fpluginfile.php} \% 2 \mathrm{~F} 205 \%$ 2 Fmod_resource $\% 2$ Fcontent $\% 2$ F $4 \% 2$ Fnfz_o_zdrowiu_cukrzyca. pdf\&usg=AOvVaw0Xd59I4iVoJ1EN7756D9rW. Accessed November 16, 2020.

4. Brown AF, Mangione CM, Saliba D, Sarkisian CA; California Healthcare Foundation/American Geriatrics Society Panel on Improving Care for Elders with Diabetes. Guidelines for improving the care of the older person with diabetes mellitus. J Am Geriatr Soc. 2003;51(Suppl. Guidelines):S265-S2802. doi:10.1046/j.1532-5415.51.5s.1.x

5. Rokicka D, Wróbel M, Szymorska-Kajanek A, Bożek A, Strojek K. Assessment of compliance to self monitoring of blood glucose in type 2 diabetic patients and level of implementation of Polish Diabetes Association Recommendation for general practitioners - results of multicenter, prospective educational health programme - DIABCON study. Clin Diabetol. 2018;7(3):129-135. doi:10.5603/DK.2018.0008

6. Ishak NH, MohdYusoff SS, Rahman RA, Kadir AA. Diabetes self-care and its associated factors among elderly diabetes in primary care. J Taibah Univ Med Sci. 2017;12(6):504-511. doi:10.1016/j.jtumed.2017.03.008

7. Świątoniowska-Lonc N, Dudek K, Szymczyk A, Jankowska-Polańska B. Factors associated with adherence in patients with type 2 diabetes mellitus. J Educ Health Sport. 2018;8(12):192-209. doi:10.5281/ zenodo. 2093318.
8. Dudzińska M, Tarach JS, Malicka J, et al. Assessment of changes in self-control among patients with type 2 diabetes after the introduction of insulin therapy - a prospective study. Fam Med Prim Care Rev. 2013;15(3):315-317.

9. Ausili D, Barbaranelli C, Rossi E, et al. Development and psychometric testing of a theory-based tool to measure self-care in diabetes patients: the self-care of diabetes inventory. BMC Endocr Disord. 2017;17(1):66.

10. American Diabetes Association. 4. Comprehensive medical evaluation and assessment of comorbidities: standards of medical care in diabetes-2019. Diabetes Care. 2019;42(Supplement 1):34-45. doi:10.2337/dc19-S004

11. van Bussel FCG, Backes WH, van Veenendaal TM, et al. Functional brain networks are altered in type 2 diabetes and prediabetes: signs for compensation of cognitive decrements? The Maastrict Study. Diabetes. 2016;65(8):2404-2413. doi:10.2337/db16-0128

12. Yaffe K, Falvey CM, Hamilton N, et al. Association between hypoglycemia and dementia in a biracial cohort of older adults with diabetes mellitus. JAMA Intern Med. 2013;173:1300-1306. doi:10.1001/jamainternmed.2013.6176

13. Munshi MN Cognitive dysfunction in older adults with diabetes: what a clinician needs to know; 2021. Available from: https://care. diabetesjournals.org/content/40/4/461. Accessed January 08, 2021.

14. Punthakee Z, Miller ME, Launer LJ. Poor cognitive function and risk of severe hypoglycemia in type 2 diabetes. Post hoc epidemiologic analysis of the ACCORD trial. Diabetes Care. 2012;35(4):787-793. doi:10.2337/dc11-1855

15. Chatterjee S, Peters SA, Woodward M, et al. Type 2 diabetes as a risk factor for dementia in women compared with men: a pooled analysis of 2.3 million people comprising more than 100,000 cases of dementia. Diabetes Care. 2016;39(2):300-307. doi:10.2337/dc15-1588

16. Biessels GJ, Deary IJ, Ryan CM. Cognition and diabetes: a lifespan perspective. Lancet Neurol. 2008;7(2):184-190. doi:10.1016/S14744422(08)70021-8

17. Moheet A, Mangia S, Seaquist ER. Impact of diabetes on cognitive function and brain structure. Ann NY Acad Sci. 2015;1353:60-71. doi: $10.1111 /$ nyas. 12807

18. Kodl KT, Seaquist ER. Cognitive dysfunction and diabetes mellitus. EndocrRev. 2008;29:494-511.

19. Thabit H, Kennelly SM, Bhagarva A, et al. Utilization of Frontal Assessment Battery and Executive Interview 25 in assessing for dysexecutive syndrome and its association with diabetes self-care in elderly patients with type 2 diabetes mellitus. Diabetes Res Clin Pract. 2009;86:208-212. doi:10.1016/j.diabres.2009.09.004

20. Williams B, Mancia G, Spiering W, et al. 2018 ESC/ESH guidelines for the management of arterial hypertension The Task Force for the management of arterial hypertension of the European Society of Cardiology (ESC) and the European Society of Hypertension (ESH). Eur Heart J. 2018:1-98. doi:10.1093/eurheartj/ehy339.

21. Uchmanowicz I, Krzemińska S, Ausili D, Luciani M, Lisiak M. Polish adaptation of the Self-Care of Diabetes Inventory (SCODI). Patient Prefer Adherence. 2020;14:1341-1350. doi:10.2147/PPA.S253444

22. Folstein MF, Folstein SE, McHugh PR. Mini-mental state. A practical method for grading the cognitive state of patients for the clinician. J Psychiatry Res. 1975;12:189-198. doi:10.1016/0022-3956(75)90026-6

23. Kripalani S, Risser J, Gatti ME, Jacobson TA. Development and 486 evaluation of the Adherence to Refills and Medications Scale (ARMS) among low-487 literacy patients with chronic disease. Value Health. 2009;12(1):118-123. doi:10.1111/j.1524-4733.2008.00400.x

24. Sinclair AJ, Girling AJ, Bayer A. Cognitive dysfunction in older subjects with diabetes mellitus: impact on diabetes self-management and use of care services. Diabetes Res Clin Pract. 2000;50:203-212. doi:10.1016/S0168-8227(00)00195-9

25. Feil DG, Pearman A, Victor T, et al. The role of cognitive impairment and caregiver support in diabetes management of older outpatients. Int J Psychiatry Med. 2009;39:199-214. doi:10.2190/PM.39.2.h 
26. Trimble LA, Sundberg S, Markham L, Janicijevic S, Beattie L, Meneilly GS. Value of the clock drawing test to predict problems with insulin skills in older adults. Can J Diabetes. 2005;29:102-104.

27. Karter AJ, Ferrara A, Darbibian JA, et al. Self-monitoring of blood glucose. Language and financial barriers in managed care population with diabetes. Diabetes Care. 2000;23:477-483. doi:10.2337/diacare. 23.4.477

28. Schaie KW. Developmental Influences on Adult Intelligence: The Seattle Longitudinal Study. New York, NY, USA: Oxford University Press; 2005.

29. Ott A, Stolk RP, Hofman A, van Harskamp F, Grobbee DE, Breteler MM. Association of diabetes mellitus and dementia: the Rotterdam Study. Diabetologia. 1996;39:1392-1397. doi:10.1007/s001250050588

30. Arvanitakis Z, Wilson RS, Bennett DA. Diabetes mellitus, dementia, and cognitive function in older persons. $J$ Nutr Health Aging. 2006;10(4):287-291.

31. Hewitt J, Smeeth L, Chaturvedi N, Bulpitt CJ, Fletcher AE. Selfmanagement and patient understanding of diabetes in the older person. Diabet Med. 2011;28:117-122. doi:10.1111/j.1464-5491.20 10.03142.x

32. Compeán-Ortiz LG, Gallegos EC, Gonzalez-Gonzalez JG, Gomez-Meza M, Therrien B, Salazar BC. Cognitive performance associated with self-care activities in Mexican adults with type 2 diabetes. Diabetes Educ. 2010;36(2):268-275. doi:10.1177/0145721710361783

33. Snyder HM, Corriveau RA, Craft S, et al. Vascular contributions to cognitive impairment and dementia including Alzheimer's disease. Alzheimers Dement. 2015;11(6):710-717. doi:10.1016/j.jalz.2014. 10.008
34. Nguyen HT, Grzywacz JG, Arcury TA, et al. Linking glycemic control and executive function in rural older adults with diabetes mellitus. J Am Geriatr Soc. 2010;58:1123-1127. doi:10.1111/j.153 2-5415.2010.02857.x

35. Rosen MI, Beauvais JE, Rigsby MO, Salahi JT, Ryan CE, Cramer JA. Neuropsychological correlates of suboptimal adherence to metformin. J Behav Med. 2003;26:349-360. doi:10.1023/A:10242 57027839

36. Kazlauskaite R, Soni S, Evans AT, Graham K, Fisher B. Accuracy of self-monitored blood glucose in type 2 diabetes. Diabetes Technol Ther. 2009;11:385-392. doi:10.1089/dia.2008.0111

37. Ghisletta P, Bickel JF, Lövdén M. Does activity engagement protect against cognitive decline in old age? Methodological and analytical considerations. J Gerontol. 2006;61(5):253-261. doi:10.1093/geronb/ 61.5.P253

38. Teixeira MM, Passos VMA, Barreto SM, et al. Association between diabetes and cognitive function at baseline in the Brazilian Longitudinal Study of Adult Health (ELSA- Brasil). Sci Rep. 2020;10:1596. doi:10.1038/s41598-020-58332-9

39. Lippa KD, Klein HA. Portraits of patient cognition: how patients understand diabetes self-care. Can J Nurs Res. 2008;40(3):80-95.

40. Caller TA, Secore KL, Ferguson RJ, et al. Design and feasibility of a memory intervention with a focus on self-management for cognitive impairment in epilepsy. Epilepsy Behav. 2015;44:192-194. doi:10.1016/j.yebeh.2014.12.036

41. Asimakopoulou K, Hampson SE. Cognitive functioning and self management in older people with diabetes. Diabetes Spectr. 2002;15(2):116-121. doi:10.2337/diaspect.15.2.116

Diabetes, Metabolic Syndrome and Obesity: Targets and Therapy

Dovepress

\section{Publish your work in this journal}

Diabetes, Metabolic Syndrome and Obesity: Targets and Therapy is an international, peer-reviewed open-access journal committed to the rapid publication of the latest laboratory and clinical findings in the fields of diabetes, metabolic syndrome and obesity research. Original research, review, case reports, hypothesis formation, expert opinion and commentaries are all considered for publication. The manuscript management system is completely online and includes a very quick and fair peer-review system, which is all easy to use. Visit http://www.dovepress.com/testimonials.php to read real quotes from published authors.

Submit your manuscript here: https://www.dovepress.com/diabetes-metabolic-syndrome-and-obesity-targets-and-therapy-journal 